\title{
The aqueous extract of Glycyrrhiza inflata can upregulate unfolded protein response-mediated chaperones to reduce tau misfolding in cell models of Alzheimer's disease
}

This article was published in the following Dove Press journal:

Drug Design, Development and Therapy

29 February 2016

Number of times this article has been viewed

\author{
Kuo-Hsuan Changl,* \\ I-Cheng Chen ${ }^{1, *}$ \\ Hsuan-Yuan Lin ${ }^{2}$ \\ Hsuan-Chiang Chen² \\ Chih-Hsin Lin' \\ Te-Hsien Lin ${ }^{2}$ \\ Yu-Ting Weng' \\ Chih-Ying Chao' \\ Yih-Ru Wu' \\ Jung-Yaw Lin ${ }^{2}$ \\ Guey-Jen Lee-Chen ${ }^{2}$ \\ Chiung-Mei Chen' \\ 'Department of Neurology, Chang \\ Gung Memorial Hospital, Chang \\ Gung University College of Medicine, \\ ${ }^{2}$ Department of Life Science, National \\ Taiwan Normal University, Taipei, \\ Taiwan, Republic of China \\ *These authors contributed equally \\ to this work
}

Correspondence: Guey-Jen Lee-Chen

Department of Life Science, National

Taiwan Normal University, 88

Ting-Chou Rd, Sec 4, Taipei II677,

Taiwan, Republic of China

Tel +8862 77346359

Fax +886 229312904

Email t43019@ntnu.edu.tw

Chiung-Mei Chen

Department of Neurology, Chang

Gung Memorial Hospital, Chang

Gung University College of Medicine,

199 Tun-Hwa North Rd, Taipei 10507,

Taiwan, Republic of China

Tel $+8863328 \quad 1200$

Fax +886 33287226

Email cmchen@adm.cgmh.org.tw
Background: Alzheimer's disease (AD) and several neurodegenerative disorders known as tauopathies are characterized by misfolding and aggregation of tau protein. Although several studies have suggested the potential of traditional Chinese medicine (TCM) as treatment for neurodegenerative diseases, the role of TCM in treating AD and tauopathies have not been well explored.

Materials and methods: Tau protein was coupled to the DsRed fluorophore by fusing a pro-aggregation mutant of repeat domain of tau $\left(\Delta \mathrm{K} 280 \operatorname{tau}_{\mathrm{RD}}\right)$ with DsRed. The $\Delta \mathrm{K} 280 \operatorname{tau}_{\mathrm{RD}}{ }^{-}$ DsRed fusion gene was then used to generate Tet-On 293 and SH-SY5Y cell clones as platforms to test the efficacy of 39 aqueous extracts of TCM in reducing tau misfolding and in neuroprotection.

Results: Seven TCM extracts demonstrated a significant reduction in tau misfolding and reactive oxidative species with low cytotoxicity in the $\Delta \mathrm{K} 280$ tau $_{\mathrm{RD}}$-DsRed 293 cell model. Glycyrrhiza inflata and Panax ginseng also demonstrated the potential to improve neurite outgrowth in the $\triangle \mathrm{K} 280 \mathrm{tau}_{\mathrm{RD}}$-DsRed SH-SY5Y neuronal cell model. G. inflata further rescued the upregulation of $E R N 2$ (pro-apoptotic) and downregulation of unfolded-protein-response-mediated chaperones ERP44, DNAJC3, and SERP1 in $\triangle \mathrm{K} 280$ tau $_{\mathrm{RD}}$-DsRed 293 cells.

Conclusion: This in vitro study provides evidence that $G$. inflata may be a novel therapeutic for $\mathrm{AD}$ and tauopathies. Future applications of $G$. inflata on animal models of AD and tauopathies are warranted to corroborate its effect of reducing misfolding and potential disease modification. Keywords: Alzheimer's disease, tauopathy, tau misfolding, TCM extracts, G. inflata, UPRmediated chaperones

\section{Introduction}

Several neurodegenerative disorders known as tauopathies, such as Alzheimer's disease $(\mathrm{AD})$, frontotemporal dementia, progressive supranuclear palsy, and corticobasal degeneration, are characterized by abnormal aggregation of tau protein. ${ }^{1}$ In these diseases, tau becomes abnormally hyperphosphorylated and misfolded, forming insoluble aggregations. ${ }^{2}$ Such misfolded tau proteins are toxic to cells, particularly neurons, and several lines of evidence have shown that these aberrant proteins are responsible for neurodegeneration. ${ }^{2}$

Tau, mainly expressed in neurons, plays an important role in the constitution of neuronal microtubule network by assembling tubulin monomers into microtubules. ${ }^{3}$ It also provides links between microtubules and other cytoskeletal components. ${ }^{4}$ Under 
physiologic conditions, tau misfolding and aggregation are prevented by protein quality control mechanisms in different cellular compartments, such as the unfolded protein response (UPR) in the endoplasmic reticulum (ER). ${ }^{5}$ The UPR comprises an intricate signaling network meant to restore protein homeostasis in the ER. ${ }^{6}$ The presence of aggregates of misfolded tau in many neurodegenerative disorders affects UPR and other protein quality control mechanisms, leading to disrupted protein homeostasis. ${ }^{7}$ Thus, reducing abnormal tau misfolding has been considered a strategy for modifying the progression of $\mathrm{AD}$ and other tauopathies.

Encoded on chromosome 17, tau is alternatively spliced into six isoforms in the adult human brain. ${ }^{8}$ Tau binds microtubules through $\mathrm{C}$-terminal repeat domain $\left(\operatorname{tau}_{\mathrm{RD}}\right)$, which contains four highly conserved 18 -amino acid repeat domains. ${ }^{8}$ The tau $\mathrm{RD}_{\mathrm{RD}}$ has been shown to reside at the core of paired helical filaments of neurofibrillary tangles, ${ }^{8}$ and a deletion mutant $\Delta \mathrm{K} 280$ within $\operatorname{tau}_{\mathrm{RD}}\left(\Delta \mathrm{K} 280 \operatorname{tau}_{\mathrm{RD}}\right)$ has been found in patients with $\mathrm{AD}$ and other tauopathies. ${ }^{9,10}$ The overexpression of $\Delta \mathrm{K} 280$ tau $_{\mathrm{RD}}$ in $\mathrm{N} 2 \mathrm{a}$ neuroblastoma cell lines is highly prone to be misfolded and to form aggregation. ${ }^{1-13}$ Chemicals that can prevent this misfolding of $\Delta \mathrm{K} 280$ tau $_{\mathrm{RD}}$, such as anthraquinones and N-phenylamines, may be candidates for the treatment of AD and tauopathies. ${ }^{12,13}$

Increasing evidence suggests that some traditional Chinese medicine (TCM) extracts may attenuate the deterioration of AD. For instance, Polygala tenuifolia may have some protective effects against neuronal death and cognitive impairment in rats with AD. ${ }^{14}$ Uncaria rhynchophylla may be a therapeutic agent for preventing and/or curing AD through antiaggregation effects on Alzheimer's $\beta$-amyloid proteins. ${ }^{15}$ Huperzine A, an alkaloid from Huperzia serrata, is suggested to ameliorate memory and learning defects in patients with AD. ${ }^{16}$ Thus, TCM may have a complementary and an alternative role in preventing and treating AD.

As toxic conformational changes and aggregation are the earliest events in the pathogenic cascade, therapeutic approaches to identify tau aggregation inhibitors will be mostly effective in the treatment of the disease. The in vitro facilitation of tau aggregate degradation and improvement of cognitive function in patients with early stage AD using the tau aggregation inhibitor, methylthioninium, strongly support this strategy for treating AD and other tauopathies. ${ }^{17,18}$ To identify new TCM as tau aggregation inhibitors, this study established cell models for aberrant tau misfolding by overexpressing $\Delta \mathrm{K} 280$ tau $_{\mathrm{RD}}$ in human embryonic kidney (HEK) 293 and neuroblastoma SH-SY5Y cell lines. The effects of 39 TCM extracts on these cell models of tau misfolding were examined. Glycyrrhiza inflata had the effects of reducing tau misfolding and reactive oxygen species (ROS) and regulating the expressions of UPR pathway-related genes. These findings indicate the potential role of $G$. inflata as a novel herb medication for the treatment of $\mathrm{AD}$ and tauopathies.

\section{Materials and methods Preparation of TCM extracts}

The TCM extracts (NH001-NH042; Table 1) were provided by Sun Ten Pharmaceutical Co Ltd (Taipei, Taiwan, Republic of China). Briefly, $100 \mathrm{~g}$ of dried herbs was boiled with 1,500 mL of water at $100^{\circ} \mathrm{C}$ for 30 minutes and sieved using a 100 -mesh sieve. The extracts were concentrated to $100 \mathrm{~mL}$ and filtered through a $200-$ mesh sieve. The extracts were then dried by speed vacuum concentration and stored at $-20^{\circ} \mathrm{C}$ until use.

For strict quality control, all the raw herb materials were authenticated by botanists. Thin layer chromatography was used for qualitative analysis. Being crude aqueous extracts with one or more of multiple compounds within the extracts, high-performance liquid chromatography was used to identify the active constituents known in the herbs for both qualitative and quantitative analysis.

\section{pcDNA5/FRT/TO/tau ${ }_{R D}$-DsRed constructs}

$\mathrm{Tau}_{\mathrm{RD}}$ region $(+1497 \sim+1883$, XM_005275646) with four highly conserved 18-amino acid repeat domains was amplified from wild-type tau cDNA using primers $5^{\prime}$ - $\underline{\mathrm{GCG}}$ GCCGCCCCCTTCACC $\underline{A T G C A G A C A G C C C C C T G}$ CCC (NotI site and added ATG codon underlined) and

Table I Tested TCM extracts (number)

\begin{tabular}{ll}
\hline Rehmannia glutinosa (NH00I) & Andrographis paniculata (NH022) \\
Isatis indigotica (NH002) & Epimedium brevicornum (NH023) \\
Caesalpinia sappan L. (NH003) & Achyranthes bidentata (NH024) \\
Curcuma longa (NH004) & Coptidis rhizoma (NH025) \\
Ginkgo biloba (NH005) & Morus alba L. (NH026) \\
Uncaria rhynchophylla (NH006) & Rhodiola rosea (NH027) \\
Angelica sinensis (NH007) & Dioscorea opposita (NH029) \\
Gardenia jasminoides (NH008) & Gastrodia elata (NH030) \\
Liriope spicata (NH009) & Scrophularia ningpoensis Hemsl. \\
& (NH032) \\
Trichosanthis Radix (NH0I0) & Panax pseudoginseng (NH033) \\
Lycium barbarum (NH0II) & Panax ginseng (NH034) \\
Ligusticum wallichii (NH0I2) & Astragalus propinquus (NH035) \\
Salvia miltiorrhiza (NH0I3) & Polygalae Radix (NH036) \\
Paeonia lactiflora (NH0I4) & Pueraria lobata (NH037) \\
Scutellaria baicalensis (NH0I5) & Cyperus rotundus L. (NH038) \\
Eleutherococcus senticosus (NH0I6) & Cornus officinalis (NH039) \\
Polygonum multiflorum (NH0I7) & Poria cocos (NH040) \\
Huperzia serrata (NH0I8) & Alisma plantago-aquatica (NH04I) \\
Carthamus tinctorius (NH020) & Codonopsis pilosula (NH042) \\
Glycyrrhiza inflata (NH02I) & \\
\hline Abbreviation: TCM, tradiona Chine & \\
\hline
\end{tabular}

Abbreviation: TCM, traditional Chinese medicine. 
5'-GGATCCTTCAATCTTTTTATTTCCTCC (BamHI site underlined). The amplified $387 \mathrm{bp}$ tau $_{\mathrm{RD}}$ fragment was cloned into pGEM-T Easy (Promega Corporation, Fitchburg, WI, USA) and sequenced. DsRed gene was amplified from $p D s R e d-$ Monomer-C1 (Clontech Laboratories Inc, Palo Alto, CA, USA) using primers 5'-GAATTCGACAACACCGAGGACGTC (EcoRI site underlined and ATG codon removed) and 5'-CTCGAGCTACTGGGAGCCGGAGTG and sequenced after cloning in pGEM-T Easy.

A 12-amino acid (GSAGSAAGSGEF) containing linker fragment flanked by BamHI and EcoRI sites was formed by annealing a pair of complementary primers (5'-GATCCGC TGGCTCCGCTGCTGGTTCTGGCG and 5'-AATTCGC CAGAACCAGCAGCGGAGCCAGCG). The NotI-BamHI tau $_{\mathrm{RD}}$ fragment, BamHI-EcoRI linker, and EcoRI-NotI (in pGEM-T Easy) DsRed fragment were ligated into the Not I site of the pcDNA5/FRT/TO plasmid (Thermo Fisher Scientific, Waltham, MA, USA). The resulting in-frame fused $\operatorname{tau}_{\mathrm{RD}}$-DsRed was under the control of a tetracycline-regulated, hybrid human cytomegalovirus/ $\mathrm{TetO}_{2}$ promoter.

The pro-aggregation mutant $(\Delta \mathrm{K} 280)^{11}$ was introduced into pcDNA5/FRT/TO-tau ${ }_{\mathrm{RD}}$-DsRed by site-directed mutagenesis (primer 5'-GGCGGGAAGGTGCAGATAATTA AT $\underline{A A A G C T G G A T C T T A G C A A C G T C C A G, ~} \underline{\Delta}=\mathrm{AAG})$ (QuikChange XL Site-Directed Mutagenesis Kit; Stratagene, La Jolla, CA, USA) and confirmed by polymerase chain reaction (PCR) and sequencing.

\section{$\mathrm{Tau}_{\mathrm{RD}}$-DsRed transfection and thioflavine $S$ staining}

For transient expression, HEK293T cells (American Type Culture Collection [ATCC] no: CRL-11268) were cultivated in Dulbecco's Modified Eagle's Medium (DMEM) containing $10 \%$ fetal bovine serum (FBS). Cells were cultivated at $37^{\circ} \mathrm{C}$ in an incubator containing $5 \% \mathrm{CO}_{2}$. The cells were seeded in sixwell $\left(6 \times 10^{5} /\right.$ well $)$ plates, grown for 20 hours, and transfected with wild-type and $\Delta \mathrm{K} 280 \mathrm{tau}_{\mathrm{RD}}-\mathrm{DsRed}$ constructs $(4 \mu \mathrm{g} /$ well $)$ by the lipofection method (Thermo Fisher Scientific). After 48 hours, the cells were fixed with paraformaldehyde ( $4 \%$ in phosphate-buffered saline [PBS]) for 15 minutes, permeabilized with methanol $(80 \%)$ for 6 minutes at $-20^{\circ} \mathrm{C}$, and incubated with thioflavine S (0.1\%; Sigma-Aldrich Co, St Louis, MO, USA) for 5 minutes. After washing in ethanol (50\%), the cells were examined under a fluorescent microscope.

\section{Flp-In $\Delta K 280 \operatorname{tau}_{R D}$-DsRed cells and fluorescence intensity analysis}

The $\Delta \mathrm{K} 280$ tau $_{\mathrm{RD}}$-DsRed construct was used to establish Flp-In 293 cells and maintained according to the supplier's instructions (Thermo Fisher Scientific). A medium containing $5 \mu \mathrm{g} / \mathrm{mL}$ of blasticidin and $100 \mu \mathrm{g} / \mathrm{mL}$ of hygromycin (Thermo Fisher Scientific) was used to grow these cells. $\Delta \mathrm{K} 280 \mathrm{tau}_{\mathrm{RD}}$-DsRed 293 cells were plated into 96-well $\left(2 \times 10^{4} /\right.$ well) plates, grown for 24 hours, and pretreated with Congo red $(1-20 \mu \mathrm{M})$ or TCM extracts (NH001-NH042; $100-500 \mu \mathrm{g} / \mathrm{mL}$ ) for 8 hours. Doxycycline (Dox; $1 \mu \mathrm{g} / \mathrm{mL}$, BD, Franklin Lakes, NJ, USA) was then added to the medium to induce $\operatorname{tau}_{\mathrm{RD}}$-DsRed expression for 3 days. The cells were stained with Hoechst $33342(0.1 \mu \mathrm{g} / \mathrm{mL}$; Sigma-Aldrich Co). Images of the cells were automatically obtained and analyzed using a high-content analysis system (ImageXpress MICRO; Molecular Devices LLC, Sunnyvale, CA, USA), with excitation/emission wavelengths at $543 / 593 \mathrm{~nm}$.

\section{Real-time PCR analysis}

Total RNA from $\Delta \mathrm{K} 280 \mathrm{tau}_{\mathrm{RD}}$-DsRed cells was extracted using Trizol reagent (Thermo Fisher Scientific). After DNase (Stratagene) treatment, the RNA was quantified and reverse transcribed to cDNA using a High-Capacity cDNA Reverse Transcription Kit (Thermo Fisher Scientific). Real-time PCR amplification was performed on $100 \mathrm{ng}$ cDNA with customized probe for DsRed (forward primer: GGTGCAGCAGGACTCCT; reverse primer: GCCCTTGAACTTCACCTTGTAGAT, reporter: CAGGACGGCACCTTC) and TaqMan fluorogenic probe 4326321E for hypoxanthine phosphoribosyl transferase 1 (endogenous control; Thermo Fisher Scientific) using ABI PRISM $^{\circledR} 7000$ Sequence Detection System (Thermo Fisher Scientific). Fold change was calculated using the following formula: $2^{\Delta C t}, \Delta C_{t}=C_{t}$ (control) $-C_{t}$ (target), where $C_{t}$ indicates cycle threshold.

\section{Cell proliferation assay}

HEK293 cells (ATCC no: CRL-1573) were cultivated in DMEM containing 10\% FBS. Human neuroblastoma SH-SY5Y cells (ATCC no: CRL-2266) were maintained in DMEM F12 supplemented with 10\% FBS. Cells $\left(5 \times 10^{4} /\right.$ well in 48 -well plates $)$ were treated with different concentrations of the TCM extracts (NH008, NH014, NH016, NH021, NH027, NH034, and NH037; 5-30 mg/mL) for 1 day. Cell proliferation was measured based upon the reduction in the tetrazolium salt, 3-(4,5-dimethylthiazol-2-yl)-2,5-diphenyltetrazolium bromide ( $5 \mathrm{mg} / \mathrm{mL}$ in PBS; Sigma-Aldrich Co). The absorbance of the insoluble purple formazan product was measured at $570 \mathrm{~nm}$ by a Bio-Tek $\mu$ Quant Universal Microplate Spectrophotometer. 


\section{ROS analysis}

Tet-On $\Delta \mathrm{K} 280$ tau $_{\mathrm{RD}}$-DsRed 293 cells were plated into 12 -well $\left(1.6 \times 10^{5}\right.$ cells/well) plates, grown for 24 hours, and treated with Congo red $(20 \mu \mathrm{M})$ or TCM extracts (NH008, NH014, NH016, NH021, NH027, NH034, and NH037; $500 \mu \mathrm{g} / \mathrm{mL}$ ) for 8 hours, followed by induced tau $\mathrm{RD}$-DsRed expression with Dox $(1 \mu \mathrm{g} / \mathrm{mL})$. Three days later, fluorogenic $2^{\prime}, 7^{\prime}$-dichlorodihydrofluorescein diacetate $(30 \mu \mathrm{M}$; Thermo Fisher Scientific) designed to reliably measure ROS in live cells was added to the cells and incubated at $37^{\circ} \mathrm{C}$ for 30 minutes. The cells were then washed with PBS and analyzed for green fluorescence on a flow cytometry (BD), with excitation/emission wavelengths at 492-495/517-527 nm. In each sample, $5 \times 10^{4}$ cells were analyzed.

\section{$\mathrm{Tau}_{\mathrm{RD}}$-DsRed SH-SY5Y cells and neuronal phenotype examination}

Human SH-SY5Y-derived Flp-In host cells ${ }^{19}$ were cultivated in DMEM-F12 containing $10 \% \mathrm{FBS}, 500 \mu \mathrm{g} / \mathrm{mL}$ of geneticin (G418), and $5 \mu \mathrm{g} / \mathrm{mL}$ of blasticidin. The SH-SY5Y host cells were used to generate and maintain the $\Delta \mathrm{K} 280 \mathrm{tau}_{\mathrm{RD}}$-DsRed line as described. SH-SY5Y tau RD -DsRed cells were seeded with all trans-retinoic acid (10 $\mu \mathrm{M}$; Sigma-Aldrich Co) in six-well $\left(1 \times 10^{5} /\right.$ well $)$ plates.

On the next day, the cells were treated with Congo red $(20 \mu \mathrm{M})$ or TCM extracts (NH008, NH014, NH016, NH021, NH027, NH034, and NH037; $500 \mu \mathrm{g} / \mathrm{mL}$ ) for 8 hours. The $\operatorname{tau}_{\mathrm{RD}}$-DsRed expression was induced with Dox $(1 \mu \mathrm{g} / \mathrm{mL})$ for 1 week. The cells were then fixed in $4 \%$ paraformaldehyde, permeabilized with $0.1 \%$ Triton $\mathrm{X}-100$, blocked in $3 \%$ bovine serum albumin, and stained with primary anti-TUBB3 (neuronal class III $\beta$-tubulin) antibody (1:1,000; Covance, Princeton, NJ, USA) at $4{ }^{\circ} \mathrm{C}$ overnight and secondary anti-rabbit Alexa Fluor ${ }^{\circledR} 555$ antibody (1:500; Molecular Probes, Thermo Fisher Scientific) at room temperature for 3 hours. The total neurite outgrowth of untreated/treated cells was assessed using Metamorph Microscopy Automation and Image Analysis Software (Molecular Devices LLC).

\section{Pathway-focused gene expression analysis} Total RNA from SH-SY $5 Y \Delta K 280$ tau $_{R D}$-DsRed cells (uninduced, induced, and NH021 treated) was extracted and quantified as described. Reverse transcription was conducted using $\mathrm{RT}^{2}$ First Strand Kit (Qiagen NV, Venlo, the Netherlands), and the resulting cDNA was submitted for real-time quantitative PCR reactions on the human UPR Plus PCR Array
(Qiagen) to assay gene expression changes. Samples were added to the reaction plates following the manufacturer's instructions. The experiment was performed in triplicate for each group on the ABI PRISM ${ }^{\circledR}$ StepOnePlus Real-Time PCR System (Thermo Fisher Scientific). The analysis was performed using the spreadsheet provided by Qiagen.

\section{Western blot analysis}

Total proteins were prepared using lysis buffer containing $10 \mathrm{mM}$ of Tris- $\mathrm{HCl} \mathrm{pH} 7.5,150 \mathrm{mM}$ of $\mathrm{NaCl}, 5 \mathrm{mM}$ of ethylenediaminetetraacetic acid $\mathrm{pH} 8.0,0.1 \%$ sodium dodecyl sulfate, $1 \%$ sodium deoxycholate, 1\% NP-40, and a protease inhibitor mixture (Sigma-Aldrich $\mathrm{Co}$ ). Proteins $(20 \mu \mathrm{g})$ were separated on $10 \%$ sodium dodecyl sulfate-polyacrylamide gel electrophoresis and transferred onto nitrocellulose membranes (Schleicher and Schuell $\mathrm{GmbH}$, Dassel, Germany) by reverse electrophoresis. After being blocked, the membrane was probed with tau (1:2,000 dilution; Dako Denmark A/S, Glostrup, Denmark), ERN2 (1:500 dilution; Abcam, Cambridge, UK), ERP44 (1:500 dilution; GeneTex Inc, Irvine, CA, USA), DNADJ3 (1:500 dilution, GeneTex Inc), SERP1 (1:1,000 dilution; Abcam), $\beta$-Actin (1:5,000; EMD Millipore, Billerica, MA, USA), or glyceraldehyde-3-phosphate dehydrogenase (1:1,000 dilution; MDBio Inc, Taipei, Taiwan) at $4^{\circ} \mathrm{C}$ overnight. After extensive washing, the immune complexes were detected by horseradish peroxidase-conjugated goat anti-rabbit immunoglobulin $\mathrm{G}$ antibody (1:5,000 dilution; GeneTex Inc) and chemiluminescence substrate (EMD Millipore).

\section{Statistical analysis}

For each set of values, data were expressed as mean \pm standard deviation. Three independent experiments were performed, and differences between the groups were evaluated by Student's $t$-test or one-way analysis of variance with post hoc least significant difference test, where appropriate. Statistical significance was set at $P<0.05$.

Institutional ethical approval was not needed for cell study.

\section{Results \\ Cloning and expression of tau $\mathrm{RD}-\mathrm{DsRed}$ constructs}

To establish a cell model targeting tau misfolding, tau repeat domains $\left(\operatorname{tau}_{\mathrm{RD}}\right)$ with/without mutation $\Delta \mathrm{K} 280^{11}$ were cloned (Figure 1A) and fused in frame with DsRed (Figure 1B). To examine the misfolding of $\operatorname{tau}_{\mathrm{RD}}$, $\operatorname{tau}_{\mathrm{RD}}$-DsRed constructs were transiently expressed in HEK293T cells and probed 


\section{A}

\section{Wild type}

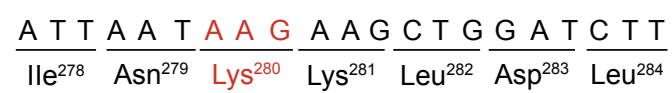

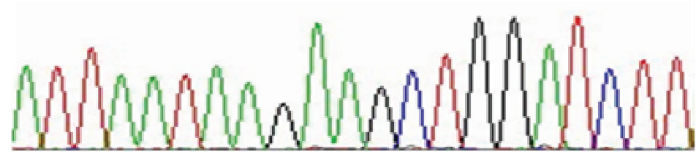

$\Delta \mathrm{K} 280$

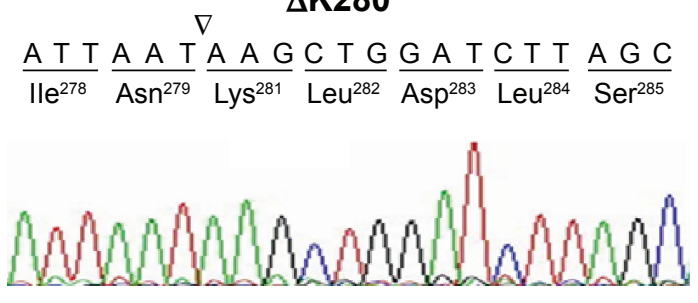

B

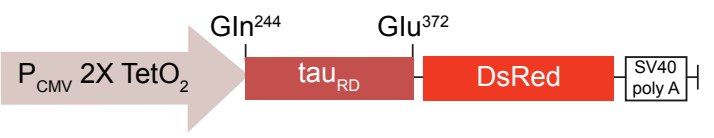

C

DsRed

Thioflavine S

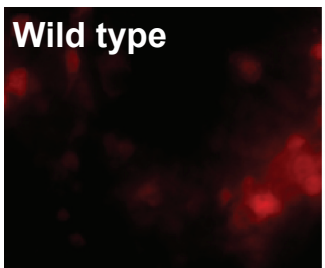

$\Delta K 280$
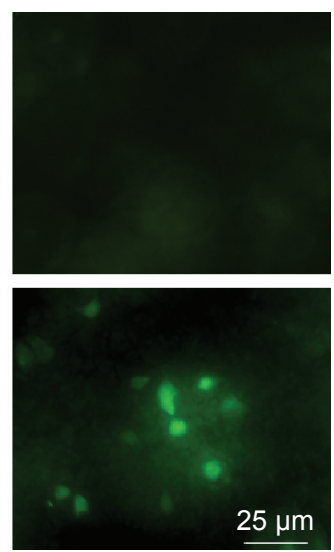

Figure I Misfolded aggregation by $\Delta K 280$ tau $_{R D}$ in HEK293T cells.

Notes: (A) Chromatograms of DNA sequencing of wild type and $\Delta K 280$ tau ${ }_{R D}$ (B) Expression plasmid with the tau ${ }_{R D}-D_{s} R^{2}$ ed downstream of $C M V / T e t O{ }_{2}$ promoter. The $\mathrm{tau}_{\mathrm{RD}}$ contained a four-repeat domain $\left(\mathrm{Gln}^{244}-\mathrm{Glu}^{372}\right)$ involved in microtubule binding and paired helical filament aggregation. (C) Expression and aggregation of wild type and $\triangle \mathrm{K} 280$ tau $_{\mathrm{RD}}$-DsRed in HEK293T cells. Tau aggregation was monitored by thioflavine $\mathrm{S}$ staining (green).

Abbreviations: $\mathrm{CMV}$, cytomegalovirus; $\mathrm{HEK}$, human embryonic kidney; $\Delta \mathrm{K} 280$, deletion of the lysine residue at codon 280 ; tau ${ }_{\mathrm{RD}}$, tau repeat domain.

by thioflavine $\mathrm{S}$ for fluorescence microscopy examination. The expressed $\Delta \mathrm{K} 280$ tau $_{\mathrm{RD}}$-DsRed protein induced a strong reaction with thioflavine $\mathrm{S}$ (Figure $1 \mathrm{C}$ ), a potential indicator of tau misfolding. ${ }^{20}$

\section{Tet-On $\Delta K 280$ tau $_{\mathrm{RD}}$-DsRed 293 cells}

A HEK293-derived Flp-In cell line was used to generate Tet-On $\Delta \mathrm{K} 280 \mathrm{tau}_{\mathrm{RD}}$-DsRed cells as neuron-specific mRNAs expression $^{21}$ and tau aggregation ${ }^{22}$ were observed in HEK293 cells. After inducing $\Delta \mathrm{K} 280 \mathrm{tau}_{\mathrm{RD}}$-DsRed expression for 2 days, tau antibody detected an apparent $43 \mathrm{kDa}^{t_{a}} \mathrm{RD}_{\mathrm{RD}}$-DsRed fusion protein by immunoblotting (Figure 2A). The lower molecular weight tau-reactive band might represent a degradation product. The real-time PCR quantification revealed a tenfold increase in $\Delta \mathrm{K} 280$ tau $_{\mathrm{RD}}$-DsRed RNA expression level after induction with Dox for 2 days (Figure 2B).

In tau $\mathrm{RD}_{\mathrm{RD}}$-DsRed-expressing cells, DsRed fluorescence was used to reflect tau aggregation status as tau aggregated rapidly to cause the fused DsRed misfolded. The inhibition of tau aggregation might improve DsRed misfolding, leading to increasing fluorescence on tau $\mathrm{RD}_{\mathrm{RD}}$-DsRed-expressing cells. Fluorescent images of Tet-On $\Delta \mathrm{K} 280 \mathrm{tau}_{\mathrm{RD}}$-DsRed cells with/without Congo red treatment $(10 \mu \mathrm{M})$ are shown in Figure $2 \mathrm{C}$. The quantification of relative fluorescent intensity revealed significantly increased DsRed fluorescence in the Congo-red-treated cells compared with the untreated cells (Figure 2D; 110\% vs 100\%; $P=0.019$ ). Congo red was known to inhibit tau aggregation. ${ }^{23}$

\section{Tests of TCM extracts on reducing $\triangle \mathrm{K} 280$ tau $_{\mathrm{RD}}$ aggregation and ROS}

Tet-On $\Delta \mathrm{K} 280$ tau $_{\mathrm{RD}}$-DsRed 293 cells were used to examine 39 TCM extracts on reducing tau ${ }_{\mathrm{RD}}$ aggregation (Table 1). The cells were pretreated with different concentrations of Congo red $(1-20 \mu \mathrm{M})$ or TCM extracts $(100-500 \mu \mathrm{g} / \mathrm{mL})$ for 8 hours, followed by the induced expression of $\Delta \mathrm{K} 280 \mathrm{tau}_{\mathrm{RD}}{ }^{-}$ DsRed for 3 days (Figure 3A). Relative DsRed fluorescence and cell number of $\Delta \mathrm{K} 280 \mathrm{tau}_{\mathrm{RD}}$-DsRed expressing cells treated with Congo red or tested TCM extracts compared to the untreated were shown in Figure 3B. As a positive control, Congo red at 10-20 $\mu \mathrm{M}$ significantly increased the $\Delta \mathrm{K} 280$ tau $_{\mathrm{RD}}$-DsRed fluorescence to $109 \%-117 \%(P=0.015-0.003)$ compared with no treatment (100\%).

Significantly increased DsRed fluorescence was observed with NH011 at $100 \mu \mathrm{g} / \mathrm{mL}(108 \%, P=0.009)$, NH004 at $200 \mu \mathrm{g} / \mathrm{mL}(121 \%, P=0.025)$, NH001-003, NH006-008, NH012-014, NH016, NH017, and NH021-023 at $500 \mu \mathrm{g} / \mathrm{mL}$ (106\%-119\%, $P=0.044-0.003)$, and NH027, NH034, and NH037 at $200-500 \mu \mathrm{g} / \mathrm{mL}(108 \%-142 \%, P=0.021-0.007)$ compared with no treatment $(100 \%)$. There was no significant change in $\Delta \mathrm{K} 280 \mathrm{tau}_{\mathrm{RD}}$-DsRed RNA level with the addition of Congo red or TCM extracts (data not shown).

Suppression of oxidative stress delayed the development of tau pathology. ${ }^{24}$ Whether the selected TCM extracts reduced ROS formation in $293 \Delta \mathrm{K} 280 \mathrm{tau}_{\mathrm{RD}}$-DsRed cells was evaluated by measuring the cellular production of ROS. 
A

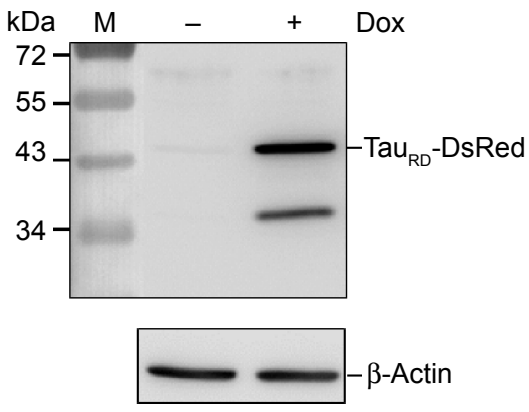

C
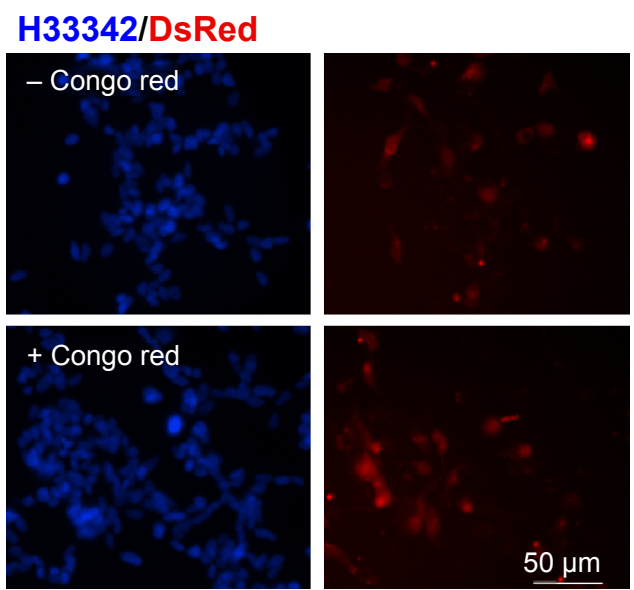

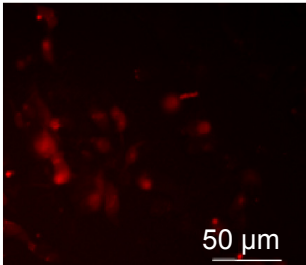

B

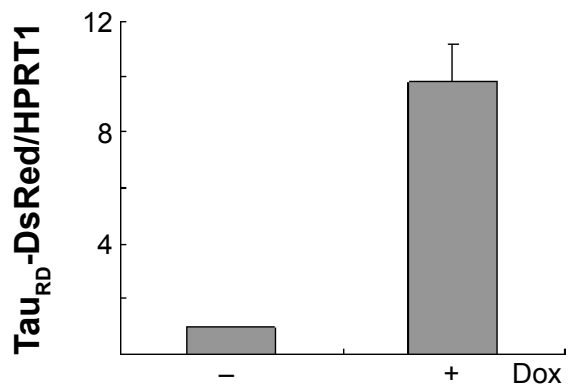

D

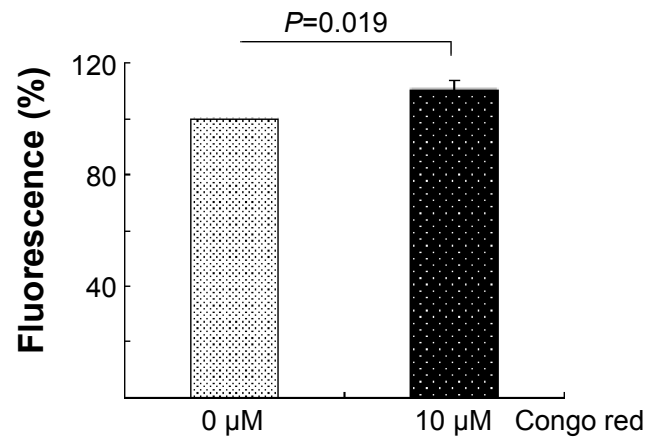

Figure 2 Tet-On $\Delta K 280$ tau $_{R D}$-DsRed 293 cell model for $A D$.

Notes: (A) Western blot analysis of $\Delta \mathrm{K} 280$ tau $_{\mathrm{RD}}$-DsRed (tau antibody staining) and $\beta$-Actin (loading control) after a 2-day induction with doxycycline (+Dox) or without doxycycline (-Dox). (B) Real-time PCR analysis ( $\mathrm{n}=3)$ of $\Delta \mathrm{K} 280$ tau $_{\mathrm{RD}}$-DsRed and HPRTI (internal control) mRNA levels after a 2-day induction with doxycycline (+Dox) or without doxycycline (-Dox). (C) Fluorescent images of $\Delta K 280$ tau $_{R D}$-DsRed cells with or without Congo red (I0 $\left.\mu M\right)$ treatment (blue, nuclei; red, expressed $\Delta K 280$ $\operatorname{tau}_{R D}-$ DsRed protein). (D) DsRed fluorescence analysis $(n=3)$ of $\Delta K 280$ tau ${ }_{R D}$-DsRed cells treated with Congo red (10 $\left.\mu M\right)$ or untreated $(0 \mu M)$. To normalize, the relative DsRed fluorescence of untreated cells was set as $100 \%$.

Abbreviations: AD, Alzheimer's disease; Dox, doxycycline; PCR, polymerase chain reaction; HPRTI, hypoxanthine phosphoribosyl transferase I; H33342, Hoechst 33342; tau $_{\mathrm{RD}}$, tau repeat domain.

The induced expression of $\Delta \mathrm{K} 280 \operatorname{tau}_{\mathrm{RD}}$-DsRed significantly increased ROS level compared with uninduced cells (112\% vs $100 \% ; P=0.021$; Figure $3 \mathrm{C}$ ). Treatment with Congo red $(20 \mu \mathrm{M})$ significantly reduced ROS level compared with no treatment ( $92 \%$ vs $112 \% ; P=0.025)$. All the selected TCM extracts $(500 \mu \mathrm{g} / \mathrm{mL})$ significantly ameliorated oxidative stress that was induced by $\Delta \mathrm{K} 280 \operatorname{tau}_{\mathrm{RD}}-\operatorname{DsRed}(91 \%-99 \%$ vs $112 \% ; P=0.046-0.001)$.

\section{Cell viability assay for half maximal inhibitory concentration cytotoxicity}

The 3-(4,5-dimethylthiazol-2-yl)-2,5-diphenyltetrazolium bromide assays were performed with human HEK293 and SH-SY5Y cells after the treatment with seven selected TCM extracts (NH008, NH014, NH016, NH021, NH027, NH034, and $\mathrm{NH} 037 ; 5-30 \mathrm{mg} / \mathrm{mL}$ ) for 24 hours. The half maximal inhibitory concentration $\left(\mathrm{IC}_{50}\right)$ was calculated using the interpolation method. $\mathrm{NH} 021$ and $\mathrm{NH} 034$ had an $\mathrm{IC}_{50}$ of $26.3 \mathrm{mg} / \mathrm{mL}$ and $>30 \mathrm{mg} / \mathrm{mL}$, respectively, in HEK293 cells and $22.9 \mathrm{mg} / \mathrm{mL}$ and $10.2 \mathrm{mg} / \mathrm{mL}$, respectively, in SH-SY5Y cells (Figure 4). Other TCM extracts had higher $\mathrm{IC}_{50}$ than the highest concentration tested $(>30 \mathrm{mg} / \mathrm{mL})$ in both HEK 293 and SH-SY5Y cells.

\section{Neurite outgrowth on Tet-On $\Delta \mathrm{K} 280$ tau $_{R D}$-DsRed SH-SY5Y cells}

The SH-SY5Y in vitro model is frequently used in neurodegenerative research. ${ }^{25}$ To test the neuroprotective potential of the selected TCM extracts, Flp-In SH-SY5Y cells with inducible $\triangle \mathrm{K} 280 \mathrm{tau}_{\mathrm{RD}}$-DsRed expression were constructed. Like the Tet-On 293 cells, $43 \mathrm{kDa} \Delta \mathrm{K} 280 \mathrm{tau}_{\mathrm{RD}}$-DsRed fusion protein and tenfold of RNA expression were observed after 2 days of induction (data not shown).

To induce neuronal differentiation, cells were differentiated with retinoic acid $(10 \mu \mathrm{M}){ }^{26}$ After 8 hours of pretreatment with Congo red/TCM extracts, followed by induced $\Delta \mathrm{K} 280 \operatorname{tau}_{\mathrm{RD}}$-DsRed expression, neurite outgrowth was analyzed. Representative fluorescence microscopy images of untreated and NH021 (G. inflata)/NH034 (Panax ginseng)/ Congo-red-treated cells are shown in Figure 5A. The induced 

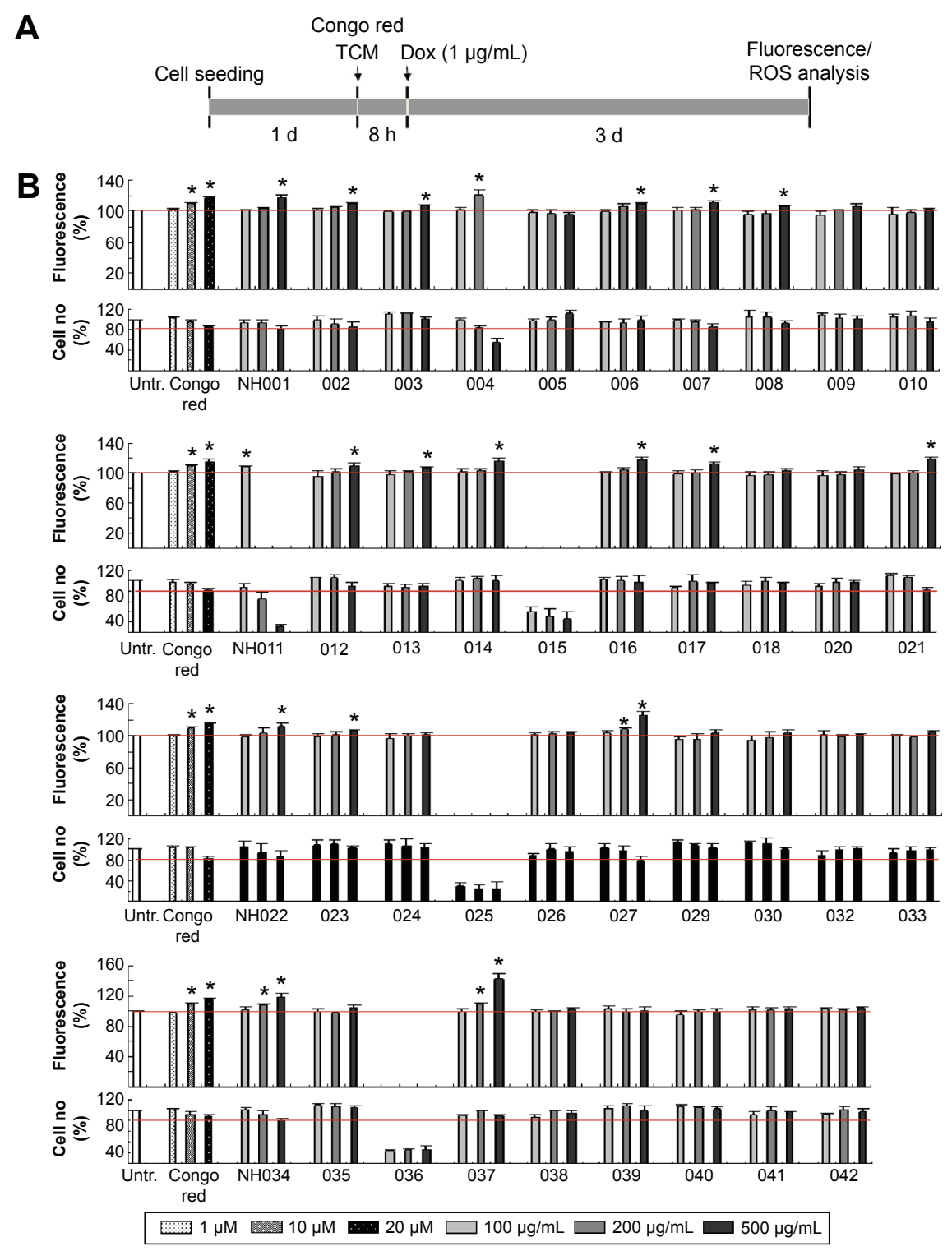

C

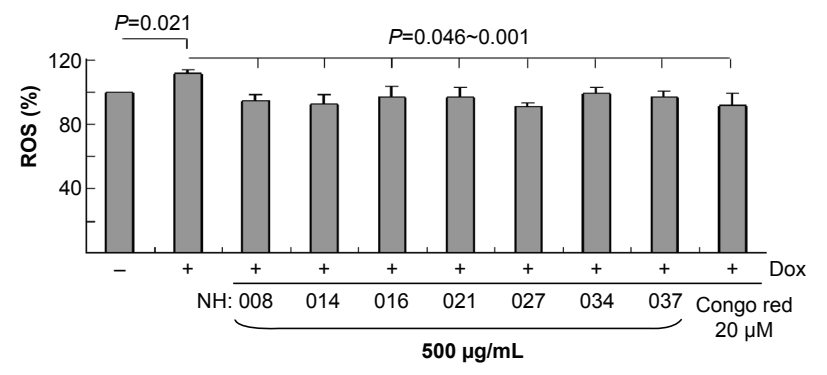

\begin{tabular}{|l|llllllllll|}
\hline & Control & Dox & NH008 & NH014 & NH016 & NH021 & NH027 & NH034 & NH037 & $\begin{array}{l}\text { Congo } \\
\text { red }\end{array}$ \\
\hline Mean & 100 & 112 & 94 & 92 & 97 & 96 & 91 & 99 & 97 & 92 \\
SD & 0 & 3 & 4 & 6 & 7 & 6 & 2 & 4 & 4 & 7 \\
Statistical analysis & & 0.021 & 0.004 & 0.014 & 0.046 & 0.039 & 0.001 & 0.011 & 0.007 & 0.025 \\
\hline
\end{tabular}

Figure 3 High-content screening of TCM extracts.

Notes: (A) Experimental flow chart. Cells were plated into 96-well plates, grown for 24 hours, and treated with different concentrations of Congo red or TCM extracts for 8 hours. Then, doxycycline $(\mathrm{I} \mu \mathrm{g} / \mathrm{mL}$ ) was added for 3 days and DsRed fluorescence was assessed by the HCA system. (B) DsRed fluorescence assay ( $\mathrm{n}=3$ ) with Congo red $(\mathrm{I}-20 \mu \mathrm{M})$ or TCM extracts (NH00I-NH042; 100-500 $\mu \mathrm{g} / \mathrm{mL})$ treatment. To normalize, the relative DsRed fluorescence of untreated cells (Untr.) was set as $100 \%$. $* \mathrm{P}<0.05$, treated vs untreated cells. (C) The cells were pretreated with Congo red $(20 \mu \mathrm{M})$ or TCM extracts $(\mathrm{NH} 008, \mathrm{NH} 0 \mathrm{I} 4, \mathrm{NH} 0 \mathrm{I} 6, \mathrm{NH} 02 \mathrm{I}, \mathrm{NH} 027, \mathrm{NH} 034$, and $\mathrm{NH} 037 ; 500 \mu \mathrm{g} / \mathrm{mL}$ ) for 8 hours and $\Delta \mathrm{K} 280$ tau $_{\mathrm{RD}}$-DsRed expression induced for 3 days for ROS measurement ( $\mathrm{n}=3$ ). $P$-values compared induced vs uninduced cells or TCM/ Congo-red-treated vs untreated cells.

Abbreviations: Dox, doxycycline; HCA, high-content analysis; ROS, reactive oxygen species; SD, standard deviation; TCM, traditional Chinese medicine. 

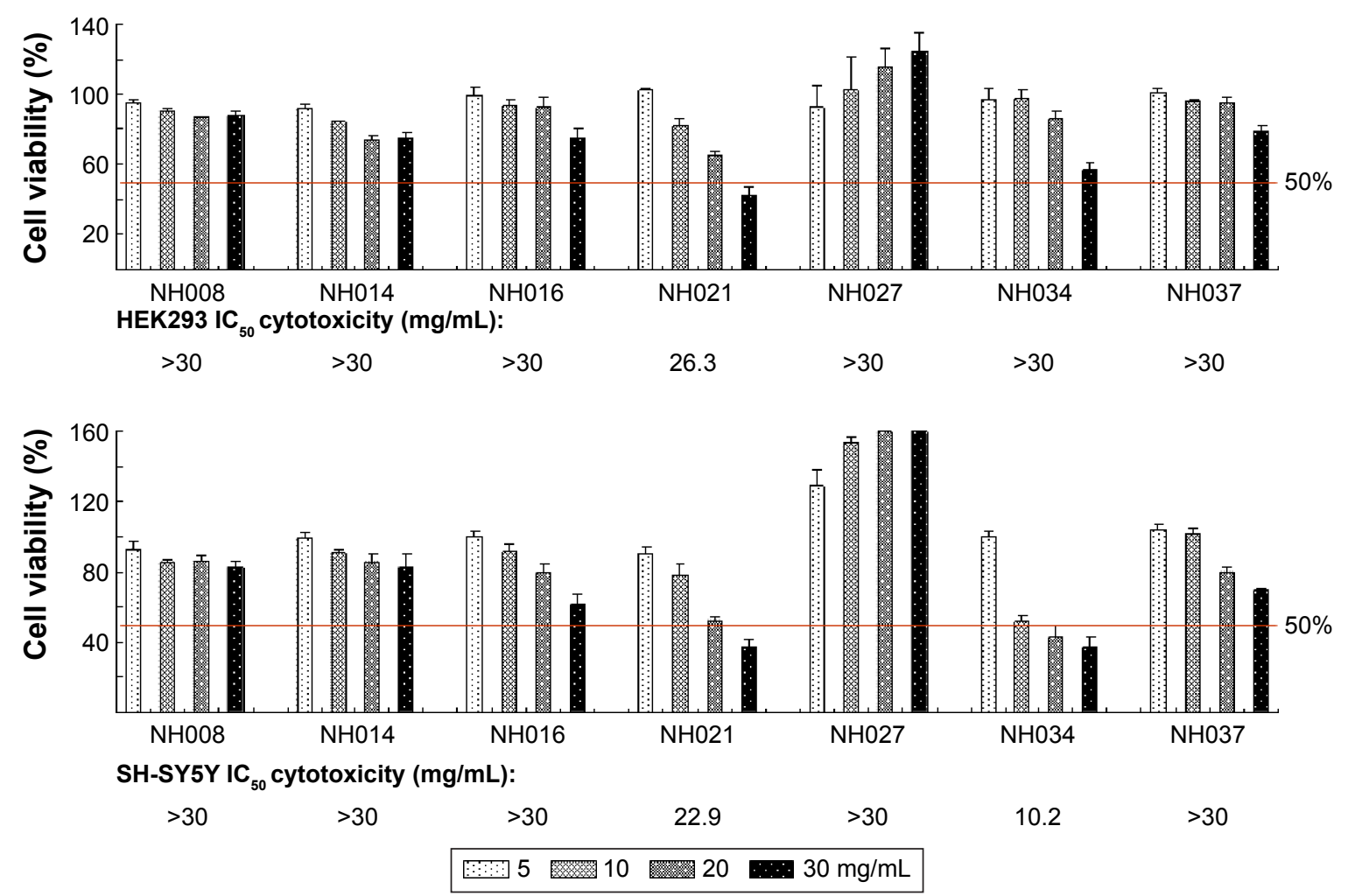

Figure 4 Cytotoxicity of the selected TCM extracts.

Notes: HEK293 and SH-SY5Y cells were treated with TCM extracts (NH008, NH0I4, NH0I6, NH02I, NH027, NH034, and NH037; 5-30 mg/mL). Cell proliferation was measured the next day using MTT viability assay $(n=3)$. To normalize, the relative viability in untreated cells was set as $100 \%$. The $I C_{50}$ of each TCM extract is shown under the columns. Red lines, $50 \%$ viability.

Abbreviations: HEK, human embryonic kidney; $I_{50}$, half maximal inhibitory concentration; MTT, 3-(4,5-dimethylthiazol-2-yl)-2,5-diphenyltetrazolium bromide; TCM, traditional Chinese medicine.

expression of $\Delta \mathrm{K} 280 \mathrm{tau}_{\mathrm{RD}}$-DsRed significantly reduced neurite outgrowth compared with the absence of induction ( $87 \%$ vs $100 \% ; P=0.012$; Figure $5 \mathrm{~B}$ ).

The treatment of Congo red $(20 \mu \mathrm{M})$ significantly improved neurite outgrowth compared with no treatment $(99 \%$ vs $87 \%$; $P=0.014$ ). Among the seven selected TCM extracts (NH021 and $\mathrm{NH} 034 ; 500 \mu \mathrm{g} / \mathrm{mL}$ ) also significantly improved neurite outgrowth in $\triangle \mathrm{K} 280 \mathrm{tau}_{\mathrm{RD}}$-DsRed-expressing SH-SY5Y cells (100\%-105\% vs $87 \% ; P=0.013-0.006)$. NH021 was selected for further evaluation because of its better neuroprotective effect in SH-SY5Y cells.

\section{UPR-related gene expression profiles in $\Delta \mathrm{K} 280 \mathrm{tau}_{\mathrm{RD}}-\mathrm{DsRed} \mathrm{SH}-\mathrm{SY} 5 \mathrm{Y}$ cells with/ without $\mathrm{NHO2}$ I treatment}

The unfolded-protein-response (UPR) pathway is affected by neurodegenerative tauopathies. The UPR-targeted PCR arrays were used to examine the effect of NH021 treatment on the expression of UPR pathway-related gene changes (Figure 6A). Of 84 tested transcripts, ERN2 showed 2.08-fold change and ERP44, DNAJC3, EIF2A, SEC62, and SERP1 showed $0.51-0.75$-fold changes in their expression levels upon induction of $\Delta \mathrm{K} 280 \mathrm{tau}_{\mathrm{RD}}$-DsRed. These fold changes were reversed with $\mathrm{NH} 021$ treatment: 0.48 -fold change for ERN2 and 1.35-1.91-fold changes for ERP44, DNAJC3, EIF2A, SEC62, and SERP1 (Table 2).

The protein levels of ERN2, ERP44, DNAJC3, and SERP1 with and without NH021 and/or Dox treatment were then examined. The protein expression of ERN2 increased $(151 \%, P=0.015)$ with the induced expression of $\Delta \mathrm{K} 280$ $\operatorname{tau}_{\mathrm{RD}}$-DsRed for 3 days (Figure 6B). The addition of NH021 rescued the ERN2 increase $(111 \%, P=0.028)$.

On the other hand, the protein expressions of ERP44, DNAJC3, and SERP1 were attenuated $(75 \%-65 \%$, $P=0.045-0.020$ ) by the induced expression of $\triangle \mathrm{K} 280 \mathrm{tau}_{\mathrm{RD}}{ }^{-}$ DsRed. The addition of NH021 rescued the reduction in ERP44, DNAJC3, and SERP1 (107\%-135\%, $P=0.039-0.027)$. Overall, these findings indicated that $\mathrm{NH} 021$ regulated $E R N 2$, ERP44, DNAJC3, and SERP1 expressions in $\triangle \mathrm{K} 280 \mathrm{tau}_{\mathrm{RD}}{ }^{-}$ DsRed cells.

\section{Discussion}

To date, effective treatments that prevent the progression of $\mathrm{AD}$ are not available. A number of TCMs have been identified 
A TUBB3/DAPI
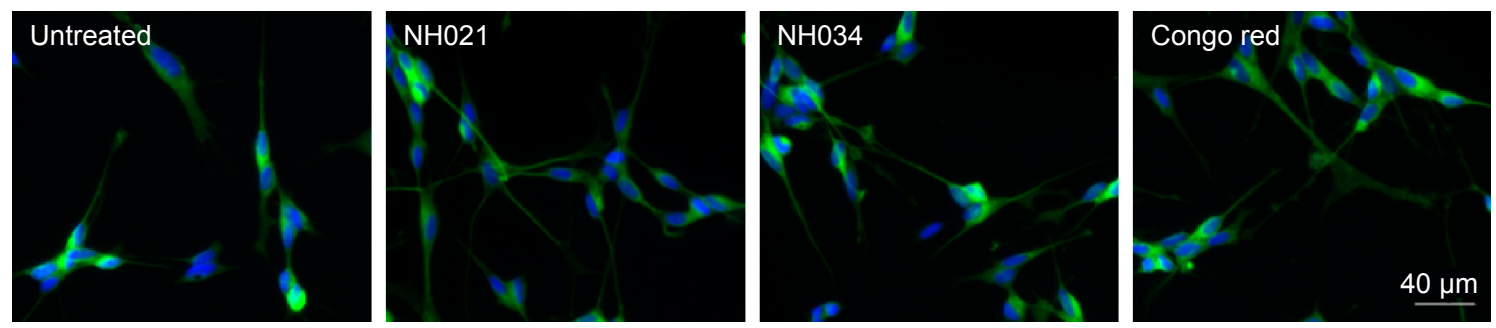

B

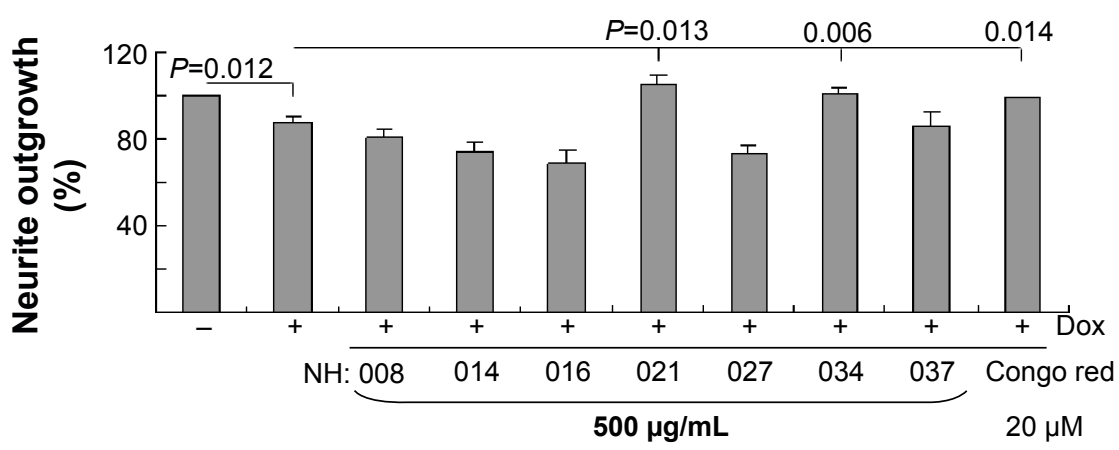

\begin{tabular}{|l|llllllllll|}
\hline & Control & Dox & NH008 & NH014 & NH016 & NH021 & NH027 & NH034 & NH037 & $\begin{array}{l}\text { Congo } \\
\text { red }\end{array}$ \\
\hline Mean & 100 & 87 & 81 & 74 & 68 & 105 & 74 & 100 & 86 & 99 \\
SD & 0 & 2 & 4 & 5 & 6 & 5 & 3 & 3 & 6 & 0 \\
Statistical analysis & & 0.012 & & & & 0.013 & & 0.006 & & 0.014 \\
\hline
\end{tabular}

Figure 5 Neuroprotective effects of the selected TCM extracts in SH-SY5Y $\Delta$ K280 tau ${ }_{R D}-D_{s}$ Red cells.

Notes: (A) Fluorescence microscopy images of differentiated SH-SY5Y cells with $\triangle \mathrm{K} 280$ tau $_{\mathrm{RD}}-\mathrm{DsRed}$ expression without or with $\mathrm{NH} 02 \mathrm{I} / \mathrm{NH} 034 / \mathrm{Congo}$ red treatment for 7 days. (B) Treatment with TCM extracts (NH008, NH0I4, NH0I6, NH02I, NH027, NH034, and NH037; $500 \mu g / \mathrm{mL}$ ), Congo red (20 $\mu$ M), and neurite outgrowth assay $(n=3)$. To normalize, the relative neurite outgrowth of uninduced cells was set as $100 \%$. $P$-values compared induced vs uninduced cells or TCM/Congo-red-treated vs untreated cells (only those with improved neurite outgrowth are shown).

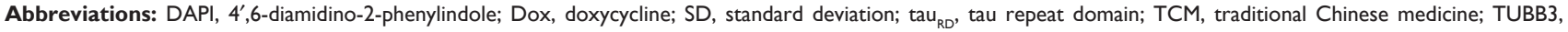
tubulin, beta 3 class III.

as potential treatment, ${ }^{27}$ but most of them target the inhibition of $\mathrm{A} \beta$ aggregation, ${ }^{28,29}$ oxidative stress, ${ }^{30}$ glutamate-induced excitotoxicity, ${ }^{31-33}$ and acetylcholinesterase. ${ }^{34}$ Tau proteins are the major components of the intraneuronal filamentous inclusions that characterize $\mathrm{AD}$ and other tauopathies. Tautargeted therapeutics provide alternative drug discovery strategies for neurodegenerative diseases. However, effective treatments that target tau misfolding are still few. This study is the first to demonstrate the role of seven novel TCMs in reducing tau misfolding and ROS in $\triangle \mathrm{K} 280 \mathrm{tau}_{\mathrm{RD}^{-}}$ DsRed 293 cells. The relatively high $\mathrm{IC}_{50}$ cytotoxicity ( 26.3 to $>30 \mathrm{mg} / \mathrm{mL})$ and low effective dose $(200-500 \mu \mathrm{g} / \mathrm{mL})$ suggest their low cytotoxicity and high misfolding inhibitory efficacy. Among these TCM, G. inflata and P. ginseng also demonstrate the potential to improve neurite outgrowth in the $\Delta \mathrm{K} 280$ tau $_{\mathrm{RD}}$-DsRed SH-SY5Y neuronal cell model. G. inflata further rescued the upregulation of pro-apoptotic transcription factor ERN2 and downregulation of UPRmediated chaperones ERP44, DNAJC3, and SERP1. These
TCMs may be regarded as new sources of treatment for AD and tauopathies.

Extracts of the roots of Glycyrrhiza species have been used as herbal medicine for peptic ulcer, hepatitis $\mathrm{C}$, diabetes mellitus, and pulmonary and skin diseases ${ }^{35}$ As one of the Glycyrrhiza species, G. inflata is known to inhibit polyglutamine aggregation by upregulating PPARGC1A and NFE2L2-ARE pathways to increase mitochondrial biogenesis and decrease oxidative stress in cell models of spinocerebellar ataxia $3 .{ }^{36}$ One of its constituents, glycyrrhizin, has been shown to have the potential to prevent 1-methyl-4-phenylpyridinium (MPP $\left.{ }^{+}\right)$ cytotoxicity by inhibiting ROS formation and restoring glutathione expression. ${ }^{37}$ This study consistently demonstrates that increased ROS in cells expressing misfolded tau can be attenuated by $G$. inflata, suggesting that this herb extract may reduce tau misfolding by reducing oxidative stress.

In patients with $\mathrm{AD}$, the activation of UPR occurs in the neurons diffusely expressing phosphorylated tau, but not in neurons containing tau aggregation. ${ }^{5}$ This indicates that UPR 
A
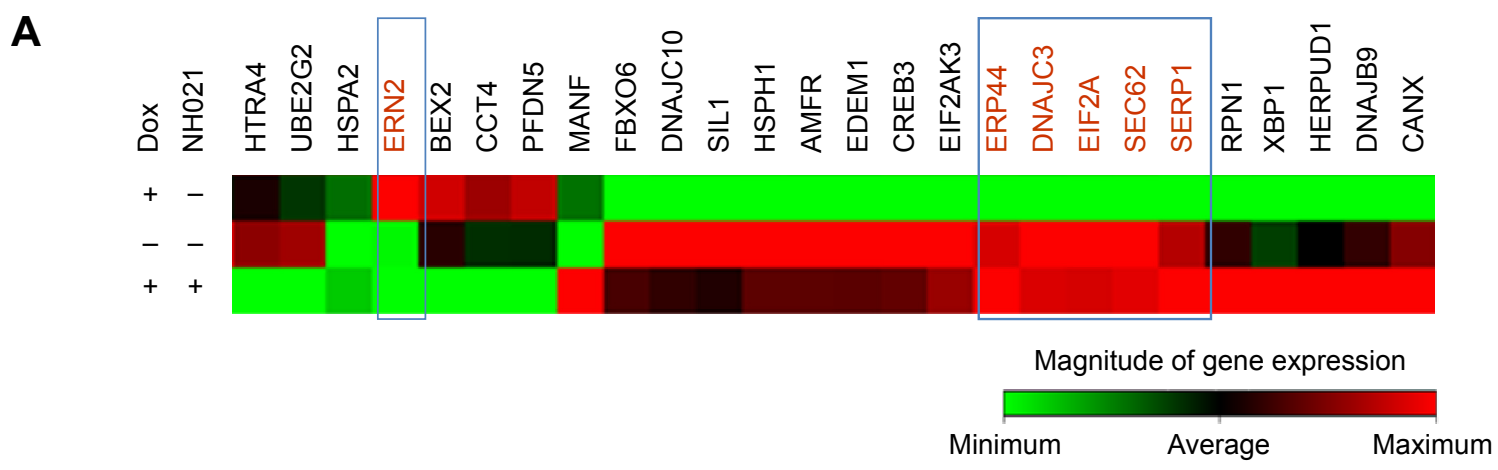

B
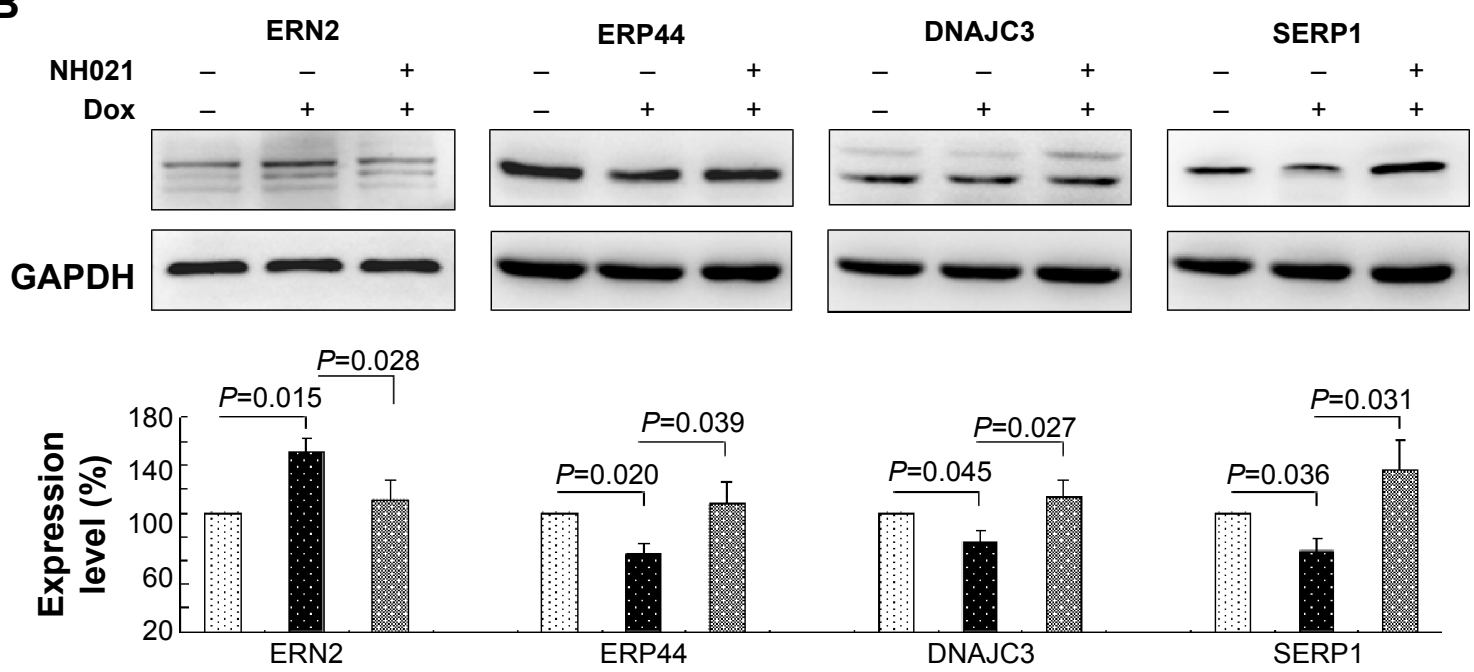

Figure 6 Alterations of UPR-related gene expression in Tet-On $\Delta$ K280 tau ${ }_{R D}-D s R e d ~ S H-S Y 5 Y$ cells.

Notes: (A) Heat map illustrating RNA expression changes in $\Delta \mathrm{K} 280$ tau $_{\mathrm{RD}}-\mathrm{DsRed}$ uninduced (-Dox, $\left.-\mathrm{NH} 02 \mathrm{I}\right)$, induced (+Dox, $\left.-\mathrm{NH} 02 \mathrm{I}\right)$, and $\mathrm{NH} 02 \mathrm{I}-$ treated (+Dox, $+\mathrm{NH} 021$ ) cells. Red shade, high expression level; green shade, low expression level. (B) Relative ERN2, ERP44, DNAJC3, and SERPI protein levels were analyzed by immunoblotting with specific antibodies. ERN2, ERP44, DNAJC3, and SERPI levels were normalized to GAPDH internal control ( $n=3$ ). The relative ERN2, ERP44, DNAJC3, and SERPI protein levels are shown below the representative Western blot images. To normalize, the expression level in uninduced (-Dox, $-\mathrm{NH} 02 \mathrm{I})$ cells was set as I00\%. Abbreviations: Dox, doxycycline; DNAJC3, DnaJ (Hsp40) homolog, subfamily C, member 3; ERN2, endoplasmic reticulum to nucleus signaling 2; ERP44, endoplasmic reticulum protein 44; GAPDH, glyceraldehyde-3-phosphate dehydrogenase; SERPI, stress-associated endoplasmic reticulum protein I; tau ${ }_{\mathrm{RD}}$, tau repeat domain; UPR, unfolded protein response.

activation disappears after the formation of tau aggregation. ${ }^{5}$ This observation is compatible with the PCR array analysis used in this study, in which most of the UPR-related gene expressions are not altered by the overexpression of misfolded tau. However, the results show upregulated ERN2 and downregulated ERP44, DNAJC3, and SERP1 by the overexpression of misfolded tau, while aqueous extract of $G$. inflata rescued these expression changes. Such observations are further recapitulated in protein levels by Western blot. $E R N 2$ has been suggested to play a role in ER stress response in mammalian cells. ${ }^{38}$ ERN2 induces translational repression through $28 \mathrm{~S}$ ribosomal RNA cleavage in response to ER stress. ${ }^{39}$ The overexpression of ERN2 activates both $\mathrm{BiP}$ and CHOP pathways and leads to the development of programmed cell death. ${ }^{38}$ Thus, it is possible that the suppression of abnormal ERN2 expression by G. inflata may

Table 2 Genes identified by the unfolded protein response plus PCR array

\begin{tabular}{lllll}
\hline Gene symbol & Refseq & Description & Fold change (Dox+/Dox-) & Fold change (NH02I+/Dox+) \\
\hline ERN2 & NM_033266 & Endoplasmic reticulum to nucleus signaling 2 & 2.08 & 0.48 \\
ERP44 & NM_0I505I & Endoplasmic reticulum protein 44 & 0.75 & 1.35 \\
DNAJC3 & NM_006260 & DnaJ (Hsp40) homolog, subfamily C, member 3 & 0.64 & 1.53 \\
EIF2A & NM_032025 & Eukaryotic translation initiation factor 2A, 65 kDa & 0.62 & 1.56 \\
SEC62 & NM_003262 & SEC62 homolog (S. cerevisiae) & 0.51 & 1.91 \\
SERPI & NM_0I4445 & Stress-associated endoplasmic reticulum protein I & 0.63 & 1.68
\end{tabular}

Abbreviations: Dox, doxycycline; PCR, polymerase chain reaction; Refseq, reference sequence; S. cerevisiae, Saccharomyces cerevisiae. 
also contribute to the protection of cells and neurons in the model used in this study.

ERP44, DNAJC3, and SERP1 play roles in promoting normal protein folding. ERP44 forms mixed disulfides with proteins involved in oxidative protein folding in the ER, including ERO1L- $\alpha$ and ERO1L- $\beta .^{38}$ In addition, ERP44 may be a sensor of ER stress, regulating the distribution patterns of cytosolic $\mathrm{Ca}^{2+}$ concentrations by modulating IP3R1 activity. ${ }^{40}$ DNAJC3 encodes a protein that acts as a co-chaperone of HSPA5, a major ER-localized HSP70 that promotes normal protein folding. ${ }^{41}$ Loss-of-function mutations in DNAJC3 result in diabetes mellitus and multisystemic neurodegeneration.

As a molecular chaperone, ${ }^{42}$ SERP1 also plays a role in pathways controlling membrane protein biogenesis at the ER. ${ }^{43}$ In 293 cells exposed to ER stress, the overexpression of SERP1 suppresses the aggregation and/or degradation of newly synthesized integral membrane proteins RAGE and CD8, subsequently facilitating their glycosylation when the stress was removed. ${ }^{43}$ SERP1 knockout mice demonstrate enhanced ER stress, growth retardation, increased mortality, and impaired glucose tolerance. ${ }^{44}$ The upregulation of ERP44, DNAJC3, and SERP1 by $G$. inflata may contribute to the improvement of cell viability and neuroprotection.

This study has several limitations. The fusion of DsRed with tau protein significantly increases the molecular size and may affect the misfolding status. Thioflavin S staining may demonstrate positive patterns that are not caused by misfolded proteins. The cell models may not fully recapitulate the phenotypes of human $\mathrm{AD}$ and other tauopathies. Therefore, the findings in this study need to be validated by other models, particularly in animals. TCM extracts are crude aqueous extracts of herbs, and hence one or more of multiple compounds within the extracts may be exerting different effects in the cell models. Since we did not show the specific effect exerted by the individual compounds within the extracts, more studies are warranted to further address this question.

\section{Conclusion}

This in vitro study provides evidence that $G$. inflata may be a novel therapeutic option for AD and other tauopathies. Aqueous extracts of $G$. inflata reduce tau misfolding and ROS production, downregulate the pro-apoptotic gene ERN2, and upregulate UPR-mediated chaperones ERP44, DNAJC3, and $S E R P 1$. Future applications of $G$. inflata to animal models of $\mathrm{AD}$ and other tauopathies are warranted to corroborate its effect on misfolding reduction and the potential prevention of disease progression.

\section{Acknowledgments}

The authors thank the Molecular Imaging Core Facility of National Taiwan Normal University for the technical assistance. This work was supported by grants from the Ministry of Science and Technology (102-2321-B-182-013, 103-2321-B-182-008, and 103-2325-B-003-001) and the National Taiwan Normal University (103T3040B05) in Taipei, Taiwan, Republic of China.

\section{Disclosure}

The authors report no conflicts of interest in this work.

\section{References}

1. Iqbal K, del C, Alonso A, et al. Tau pathology in Alzheimer disease and other tauopathies. Biochim Biophys Acta. 2005;1739(2-3):198-210.

2. Buee L, Bussiere T, Buee-Scherrer V, Delacourte A, Hof PR. Tau protein isoforms, phosphorylation and role in neurodegenerative disorders. Brain Res Brain Res Rev. 2000;33(1):95-130.

3. Weingarten MD, Lockwood AH, Hwo SY, Kirschner MW. A protein factor essential for microtubule assembly. Proc Natl Acad Sci U S A. 1975;72(5):1858-1862.

4. Miyata Y, Hoshi M, Nishida E, Minami Y, Sakai H. Binding of microtubule-associated protein 2 and tau to the intermediate filament reassembled from neurofilament $70-\mathrm{kDa}$ subunit protein. Its regulation by calmodulin. J Biol Chem. 1986;261(28):13026-13030.

5. Hoozemans JJ, van Haastert ES, Nijholt DA, Rozemuller AJ, Eikelenboom P, Scheper W. The unfolded protein response is activated in pretangle neurons in Alzheimer's disease hippocampus. Am J Pathol. 2009; 174(4):1241-1251.

6. Walter $\mathrm{P}$, Ron $\mathrm{D}$. The unfolded protein response: from stress pathway to homeostatic regulation. Science. 2011;334(6059):1081-1086.

7. Abisambra JF, Jinwal UK, Blair LJ, et al. Tau accumulation activates the unfolded protein response by impairing endoplasmic reticulumassociated degradation. J Neurosci. 2013;33(22):9498-9507.

8. Goedert M, Spillantini MG, Potier MC, Ulrich J, Crowther RA. Cloning and sequencing of the cDNA encoding an isoform of microtubule-associated protein tau containing four tandem repeats: differential expression of tau protein mRNAs in human brain. EMBO J. 1989;8(2):393-399.

9. D'Souza I, Poorkaj P, Hong M, et al. Missense and silent tau gene mutations cause frontotemporal dementia with parkinsonism-chromosome 17 type, by affecting multiple alternative RNA splicing regulatory elements. Proc Natl Acad Sci U S A. 1999;96(10):5598-5603.

10. Momeni P, Pittman A, Lashley T, et al. Clinical and pathological features of an Alzheimer's disease patient with the MAPT $\triangle \mathrm{K} 280$ mutation. Neurobiol Aging. 2009;30(3):388-393.

11. Khlistunova I, Biernat J, Wang Y, et al. Inducible expression of Tau repeat domain in cell models of tauopathy: aggregation is toxic to cells but can be reversed by inhibitor drugs. J Biol Chem. 2006;281(2): $1205-1214$.

12. Pickhardt M, Biernat J, Khlistunova I, et al. N-phenylamine derivatives as aggregation inhibitors in cell models of tauopathy. Curr Alzheimer Res. 2007;4(4):397-402.

13. Pickhardt M, Gazova Z, von Bergen M, et al. Anthraquinones inhibit tau aggregation and dissolve Alzheimer's paired helical filaments in vitro and in cells. $J$ Biol Chem. 2005;280(5):3628-3635.

14. Park CH, Choi SH, Koo JW, et al. Novel cognitive improving and neuroprotective activities of Polygala tenuifolia Willdenow extract, BT-11. J Neurosci Res. 2002;70(3):484-492. 
15. Fujiwara H, Iwasaki K, Furukawa K, et al. Uncaria rhynchophylla, a Chinese medicinal herb, has potent antiaggregation effects on Alzheimer's $\beta$-amyloid proteins. J Neurosci Res. 2006;84(2):427-433.

16. Jiang H, Luo X, Bai D. Progress in clinical, pharmacological, chemical and structural biological studies of huperzine A: a drug of traditional Chinese medicine origin for the treatment of Alzheimer's disease. Curr Med Chem. 2003;10(21):2231-2252.

17. Wischik CM, Edwards PC, Lai RY, Roth M, Harrington CR. Selective inhibition of Alzheimer disease-like tau aggregation by phenothiazines. Proc Natl Acad Sci U S A. 1996;93(20):11213-11218.

18. Wischik CM, Staff RT, Wischik DJ, et al. Tau aggregation inhibitor therapy: an exploratory phase 2 study in mild or moderate Alzheimer's disease. J Alzheimers Dis. 2015;44(2):705-720.

19. Lee LC, Chen CM, Wang PR, Su MT, Lee-Chen GJ, Chang CY. Role of high mobility group box 1 (HMGB1) in SCA17 pathogenesis. PLoS One. 2014;9(12):e115809.

20. Friedhoff P, Schneider A, Mandelkow EM, Mandelkow E. Rapid assembly of Alzheimer-like paired helical filaments from microtubuleassociated protein tau monitored by fluorescence in solution. Biochemistry. 1998;37(28):10223-10230.

21. Shaw G, Morse S, Ararat M, Graham FL. Preferential transformation of human neuronal cells by human adenoviruses and the origin of HEK 293 cells. FASEB J. 2002;16(8):869-871.

22. Bandyopadhyay B, Li G, Yin H, Kuret J. Tau aggregation and toxicity in a cell culture model of tauopathy. $J$ Biol Chem. 2007;282(22): 16454-16464.

23. Chang E, Honson NS, Bandyopadhyay B, et al. Modulation and detection of tau aggregation with small-molecule ligands. Curr Alzheimer Res. 2009;6(5):409-414.

24. Nakashima H, Ishihara T, Yokota O, et al. Effects of $\alpha$-tocopherol on an animal model of tauopathies. Free Radic Biol Med. 2004;37(2): 176-186.

25. Agholme L, Lindstrom T, Kagedal K, Marcusson J, Hallbeck M. An in vitro model for neuroscience: differentiation of SH-SY5Y cells into cells with morphological and biochemical characteristics of mature neurons. J Alzheimers Dis. 2010;20(4):1069-1082.

26. Cheung YT, Lau WK, Yu MS, et al. Effects of all-trans-retinoic acid on human SH-SY5Y neuroblastoma as in vitro model in neurotoxicity research. Neurotoxicology. 2009;30(1):127-135.

27. Cheung TS, Song TH, Ng TB, et al. Therapeutic effects of herbal chemicals in traditional Chinese medicine on Alzheimer's disease. Curr Med Chem. 2015;22(19):2392-2403.

28. Mei Z, Zhang F, Tao L, et al. Cryptotanshinone, a compound from Salvia miltiorrhiza modulates amyloid precursor protein metabolism and attenuates $\beta$-amyloid deposition through upregulating $\alpha$-secretase in vivo and in vitro. Neurosci Lett. 2009;452(2):90-95.

29. Yang F, Lim GP, Begum AN, et al. Curcumin inhibits formation of amyloid $\beta$ oligomers and fibrils, binds plaques, and reduces amyloid in vivo. J Biol Chem. 2005;280(7):5892-5901.

30. Liu JF, Yan XD, Qi LS, et al. Ginsenoside Rd attenuates $A \beta_{25-35}$-induced oxidative stress and apoptosis in primary cultured hippocampal neurons. Chem Biol Interact. 2015;239:12-18.
31. Kuang P, Wu W, Zhu K. Evidence for amelioration of cellular damage in ischemic rat brain by radix salviae miltiorrhizae treatment immunocytochemistry and histopathology studies. J Tradit Chin Med. 1993;13(1):38-41.

32. Lee MK, Kim SR, Sung SH, et al. Asiatic acid derivatives protect cultured cortical neurons from glutamate-induced excitotoxicity. Res Commun Mol Pathol Pharmacol. 2000;108(1-2):75-86.

33. Ved HS, Koenig ML, Dave JR, Doctor BP. Huperzine A, a potential therapeutic agent for dementia, reduces neuronal cell death caused by glutamate. Neuroreport. 1997;8(4):963-968.

34. Wang BS, Wang H, Wei ZH, Song YY, Zhang L, Chen HZ. Efficacy and safety of natural acetylcholinesterase inhibitor huperzine $\mathrm{A}$ in the treatment of Alzheimer's disease: an updated meta-analysis. J Neural Transm. 2009;116(4):457-465.

35. Asl MN, Hosseinzadeh H. Review of pharmacological effects of Glycyrrhiza sp. and its bioactive compounds. Phytother Res. 2008;22(6): 709-724.

36. Chen CM, Weng YT, Chen WL, et al. Aqueous extract of Glycyrrhiza inflata inhibits aggregation by upregulating PPARGC1A and NFE2L2-ARE pathways in cell models of spinocerebellar ataxia 3. Free Radic Biol Med. 2014;71:339-350.

37. Yim SB, Park SE, Lee CS. Protective effect of glycyrrhizin on 1-methyl-4-phenylpyridinium-induced mitochondrial damage and cell death in differentiated PC12 cells. J Pharmacol Exp Ther. 2007; 321(2):816-822.

38. Wang XZ, Harding HP, Zhang Y, Jolicoeur EM, Kuroda M, Ron D. Cloning of mammalian Ire1 reveals diversity in the ER stress responses. EMBO J. 1998;17(19):5708-5717.

39. Iwawaki T, Hosoda A, Okuda T, et al. Translational control by the ER transmembrane kinase/ribonuclease IRE1 under ER stress. Nat Cell Biol. 2001;3(2):158-164.

40. Higo T, Hattori M, Nakamura T, Natsume T, Michikawa T, Mikoshiba K. Subtype-specific and ER lumenal environment-dependent regulation of inositol 1,4,5-trisphosphate receptor type 1 by ERp44. Cell. 2005; 120(1):85-98.

41. Synofzik M, Haack TB, Kopajtich R, et al. Absence of BiP co-chaperone DNAJC3 causes diabetes mellitus and multisystemic neurodegeneration. Am J Hum Genet. 2014;95(6):689-697.

42. Faria D, Lentze N, Almaca J, et al. Regulation of ENaC biogenesis by the stress response protein SERP1. Pflugers Arch. 2012;463(6):819-827.

43. Yamaguchi A, Hori O, Stern DM, Hartmann E, Ogawa S, Tohyama M. Stress-associated endoplasmic reticulum protein 1 (SERP1)/Ribosomeassociated membrane protein 4 (RAMP4) stabilizes membrane proteins during stress and facilitates subsequent glycosylation. J Cell Biol. 1999; 147(6):1195-1204

44. Hori O, Miyazaki M, Tamatani T, et al. Deletion of SERP1/RAMP4, a component of the endoplasmic reticulum (ER) translocation sites, leads to ER stress. Mol Cell Biol. 2006;26(11):4257-4267.
Drug Design, Development and Therapy

\section{Publish your work in this journal}

Drug Design, Development and Therapy is an international, peerreviewed open-access journal that spans the spectrum of drug design and development through to clinical applications. Clinical outcomes, patient safety, and programs for the development and effective, safe, and sustained use of medicines are a feature of the journal, which

\section{Dovepress}

has also been accepted for indexing on PubMed Central. The manuscript management system is completely online and includes a very quick and fair peer-review system, which is all easy to use. Visit http://www.dovepress.com/testimonials.php to read real quotes from published authors. 